This is the author's final, peer-reviewed manuscript as accepted for publication. The publisher-formatted version may be available through the publisher's web site or your institution's library.

\title{
Why don't oil shocks cause inflation? Evidence from disaggregate inflation data
}

Lance Bachmeier, Inkyung Cha

\section{How to cite this manuscript}

If you make reference to this version of the manuscript, use the following information:

Bachmeier, L., \& Cha, I. (2011). Why don't oil shocks cause inflation? Evidence from disaggregate inflation data. Retrieved from http://krex.ksu.edu

\section{Published Version Information}

Citation: Bachmeier, L., \& Cha, I. (2011). Why don't oil shocks cause inflation? Evidence from disaggregate inflation data. Journal of Money, Credit and Banking, 43(6), 1165-1183.

Copyright: @ 2011 The Ohio State University

Digital Object Identifier (DOI): doi:10.1111/j.1538-4616.2011.00421.x

Publisher's Link:

http://onlinelibrary.wiley.com/doi/10.1111/j.1538-4616.2011.00421.x/full

This item was retrieved from the K-State Research Exchange (K-REx), the institutional repository of Kansas State University. K-REx is available at http://krex.ksu.edu 


\title{
Why Don't Oil Shocks Cause Inflation? Evidence From Disaggregate Inflation Data
}

\author{
Lance Bachmeier \\ Inkyung Cha
}

Kansas State University

Author Posting. (C)The Ohio State University 2011. This is the author's version of the work. It is posted here by permission of The Ohio State University for personal use, not for redistribution. The definitive version was published in the Journal of Money, Credit and Banking, vol. 43, no. 6, pp. 1165-1183. DOI: 10.1111/j.15384616.2011.00421.x

This is the working paper version plus the unpublished appendix referred to in the article. 


\title{
Why Don't Oil Shocks Cause Inflation? Evidence From Disaggregate Inflation Data
}

\author{
Lance J. Bachmeier \\ Associate Professor \\ Department of Economics \\ Kansas State University \\ Manhattan, KS 66506 \\ LanceB@ksu.edu \\ Inkyung Cha \\ Visiting Assistant Professor \\ Department of Economics \\ Kansas State University \\ Manhattan, KS 66506 \\ icha@ksu.edu
}

JEL codes: E31, E58, Q43.

Keywords: Inflation, price, oil shock, energy intensity, monetary policy, labor intensity, disaggregate, Great Inflation. 


\begin{abstract}
This paper uses disaggregate US inflation data to evaluate explanations for the breakdown of the relationship between oil price shocks and consumer price inflation. A dataset with measures of inflation, energy intensity, labor intensity, and sensitivity to monetary policy is constructed for 97 sectors that make up core CPI inflation. A comparison of the 1973-1985 and 1986-2006 time periods reveals that substitution away from energy use in production and monetary policy were both important, with approximately two-thirds of the change in response of inflation to oil shocks being due to reduced energy usage, and one-third to monetary policy. We find no evidence that other factors, such as changes in wage rigidities or changes in the persistence of oil shocks, played a role.
\end{abstract}




\section{Introduction}

It is widely believed that large oil price increases played an important role in the high US inflation rates of the 1970's (see e.g. the textbooks by Blanchard (2009) and Jones (2008). One popular explanation is that political events in the Middle East caused the price of oil to rise, raising production costs and feeding through to cause inflation in non-energy sectors of the economy. ${ }^{1}$ Panel A of Table 1 shows data on core inflation and oil prices surrounding the two oil shocks of the 1970's. The OPEC oil embargo in 1973 saw a more than doubling of the price of oil, and an increase in the core inflation rate from $2.5 \%$ in 1972 to $10.9 \%$ in 1974 . The oil price spike in 1979 was accompanied by core inflation of more than $11 \%$. It is not surprising that oil shocks have been blamed for at least some of the high inflation in this time period.

Several authors, including Blanchard and Gali (2009), De Gregorio, Landerretche, and Neilson (2007) and Hooker (2002), have shown that oil shocks are no longer followed by large increases in core inflation. Looking at Panel B of Table 1, the oil shock associated with the first Gulf War was accompanied by only a small rise in inflation, though that example might be dismissed because the oil price spike was both small and short-lived when compared with the earlier oil shocks. On the other hand, the 1996-2000 period saw unprecedented oil price volatility, yet core inflation stayed in a very tight range. The largest increase in oil prices for any of the five episodes in Table 1 occurred in the 2002-2006 period, there was no reversal of oil prices, and inflation stayed in the range of 1.2\%-2.6\%. Clearly something has changed. Knowing why this relationship broke down is important not only because oil prices have historically been a source of large shocks to the macroeconomy, but because it has broader implications for our understanding of inflation and the effects of monetary policy. 
This paper evaluates three explanations for the change in the response of inflation to oil price shocks. We have constructed a dataset on inflation, energy intensity, response to monetary policy shocks, and labor and capital shares for each of 97 sectors representing, nearly all of core consumption. We ask which factors have explanatory power for the change in response to oil shocks across sectors, and calculate the contribution of each factor to the change in the response of core CPI inflation to oil shocks. This provides a rough measure of the relative importance of each explanation for the breakdown.

The first explanation is that the large oil price increases of the 1970's led to the adoption of energy-saving technologies, reducing the importance of oil as a factor of production relative to capital, labor, and materials. It is straightforward, given the large decline in the use of energy to produce a given amount of output that has taken place over the past several decades (Sue Wing (2008)), that we should expect oil shocks to have less effect on inflation.

Second, there may have been changes in the conduct of monetary policy. The Federal Reserve may have allowed real interest rates to fall after an oil shock in the 1970's, or alternatively, aggressively offset the effects of oil shocks in recent years. Bernanke (2008) summarized the evidence on the role played by monetary policy:

"Economists generally agree that monetary policy performed poorly during this period. In part, this was because policymakers, in choosing what they believed to be the appropriate setting for monetary policy, overestimated the productive capacity of the economy." (Bernanke 2008)

As emphasized by Bernanke, Gertler and Watson (1997), evidence that monetary policy plays a role in the transmission of oil shocks implies that the systematic part of monetary policy, as opposed to just surprise changes in monetary policy, affects 
the economy. Beyond the direct response to oil shocks, the Federal Reserve may have been viewed as more committed to reducing inflation starting in the 1980's, consistent with the evidence in Clarida, et al (2000). In other words, even if there was no change in Federal Reserve policy, the public's expectation of the response of monetary policy may have changed.

Third, there may have been changes in the labor market:

"...in response to an adverse supply shock and for a given money rule, inflation will generally rise more and output will decline more, the slower real wages adjust. A trend towards more flexible labor markets, including more flexible wages, could thus explain the smaller impact of the more recent oil shocks." (Blanchard and Gali 2009)

Given the large changes that have taken place in labor markets, this is a reasonable explanation.

To our knowledge, this is the first paper to look at this question using disaggregate inflation data. The variation in characteristics across the different sectors of the US economy provides a great deal of information that is ignored when using aggregate data. Other papers on the topic (Blanchard and Gali (2009), De Gregorio, Landerretche, and Neilson (2007) and Hooker (2002)) have all used aggregate or highly aggregated data. We view this paper as complementing the work done by those authors.

We find that the change in energy intensity and sensitivity to monetary policy shocks both have explanatory power for the change in a given sector's response to oil shocks. All else constant, sectors with a bigger decline in energy intensity or a greater sensitivity to monetary policy shocks experienced a statistically significant decline in the response to oil shocks between the 1973-1985 and 1986-2006 time periods. Our 
estimates indicate that about two-thirds of the reduced response of core inflation to oil shocks can be attributed to changes in energy intensity and one-third to monetary policy. Labor intensity of production in a particular sector does not explain much of the change, suggesting that the labor market probably did not play much of a role in the change in inflation's response to oil shocks.

\section{Data}

Monthly oil price and aggregate inflation data were downloaded from Federal Reserve Economic Data (FRED) provided by the Federal Reserve Bank of St. Louis. The oil price data is the spot price of West Texas Intermediate (WTI) crude. The CPI inflation series are the percentage change in series CPIAUCSL, the Consumer Price Index For All Urban Consumers: All Items, and CPILFESL, the Consumer Price Index for All Urban Consumers: All Items Less Food and Energy.

Monthly disaggregate inflation data series were downloaded from the Bureau of Economic Analysis website, underlying detail tables, Table 2.4.4U: Chain-Type Price Indexes for Personal Consumption Expenditures. ${ }^{2}$ The data include more than 300 price indexes at several levels of aggregation, ranging from very high (durables, nondurables, and services) to very low (e.g. different types of clothing), for the period January 1959 to July 2006. We work with the lowest level of aggregation for which the entire economy is represented. After removing food and energy sectors, as well as those with incomplete data, there were 97 sectors in the final dataset.

The monetary policy shock series calculated by Romer and Romer (2004) was downloaded from the website of Professor David Romer. The other macroeconomic data used in the paper were downloaded from FRED. The unemployment rate is UNRATE, the Civilian Unemployment Rate. Industrial production growth is the per- 
centage change in series INDPRO, the Industrial Production Index. Another measure of economic activity was the first principle component of 63 monthly macroeconomic variables related to output. The list of variables is available from the authors upon request. The federal funds rate is FEDFUNDS, the Effective Federal Funds Rate.

\section{Aggregate Inflation and Oil Shocks}

\subsection{Structural Break Tests}

In Table 2 are the results of structural break tests for six highly aggregated inflation rates over the period January 1959 to July 2006, allowing for a data-determined structural break somewhere between January 1979 and December 1985 in the equation

$$
\pi_{t}=\alpha+\sum_{i=1}^{k} \beta_{i} \pi_{t-i}+\sum_{i=1}^{k} \gamma_{i} \Delta O i l_{t-i}+\varepsilon_{t} .
$$

The second and third columns are the estimated break date and corresponding ave F test statistics for the Andrews (1993) and Andrews and Ploberger (1994) structural break test. ${ }^{3}$ The last three columns are p-values for a test that all coefficients on the oil shock equal zero, with the sum of $\gamma_{i}$ for each subsample in parenthesis. Lag length in each regression was selected using the Akaike information criteria (AIC).

It is hardly surprising, in light of the previously cited studies, that we find a structural break for all of the inflation rates. The CPI, which includes energy directly, shows evidence of a structural break but does not show a "breakdown" of the relationship, in the sense of a big decrease in the sum of coefficients. In terms of both the p-values and sum of coefficients, however, there has clearly been a change in the response of the core CPI to an oil shock. PCE nondurables were sensitive at all times to oil shocks, but the response of PCE durables and services - neither of which 
directly accounts for energy prices - has largely disappeared.

We have also estimated impulse response functions using a bivariate VAR model of inflation and the change in WTI, identified by assuming the system is recursive and the oil shock has no contemporaneous effect on inflation (i.e., a Choleski decomposition with inflation first in the ordering). The impulse response functions for the core $\mathrm{CPI}$, not shown because they are neither surprising or original, show a large positive response in the pre-break period but not the post-break period.

\subsection{Discussion of Identification Restrictions}

The structural break tests and impulse response analysis discussed in the previous section were carried out on bivariate VAR models and identification of the impulse responses was achieved by applying a Choleski decomposition to the covariance matrix of the residuals. The same assumptions underlie the disaggregate analysis below, so we address objections to those assumptions. One criticism is that impulse response functions identified by a Choleski decomposition can be sensitive to the ordering of the variables. That is not the case here. The contemporaneous correlation of the residuals of the reduced form VAR models are close to zero, consistent with the recursiveness assumption that underlies the Choleski decomposition, meaning that the impulse responses are largely robust to changes in the ordering of the variables.

Another criticism is that the a bivariate VAR model omits relevant information, causing the identified oil shocks to be contaminated by shocks to macroeconomic variables other than inflation. A bivariate VAR model allows us to estimate a parsimonious model, which is important when analyzing small subsamples of the data, ${ }^{4}$ but it leaves open the possibility that important variables have been omitted.

In panel A of Table 3 is the contemporaneous correlation of the identified oil 
shock series with several macroeconomic variables, including the unemployment rate, industrial production growth, growth in the first principle component from a group of 63 macroeconomic variables, the federal funds rate, and the Romer and Romer (2004) monetary policy shock. Panel B of Table 3 summarizes regressions of the identified oil shock on the contemporaneous and lagged values of each of those series:

$$
\varepsilon_{t}^{W T I}=\alpha+\sum_{i=0}^{12} \beta_{i} x_{t-i}+\eta_{t},
$$

where $x$ is one of the macroeconomic series.

The results in Table 3 provide no support for the claim that identified oil shocks of a bivariate VAR model are contaminated with omitted information about the economy. This is consistent with the finding in Kilian (2009, Figure 3) that aggregate demand shocks have no impact on the real price of oil until eight months have passed. Motivated by the results in this section, all of the impulse response functions below are based on bivariate VAR models, identified by a Choleski decomposition with inflation first in the ordering.

\section{Which Factors Explain the Change in Response to Oil Shocks?}

There has been a change in the response of core inflation to oil shocks. In this section, we use disaggregate inflation data to evaluate three explanations for the change. We follow up with tests of two statistical explanations for the aggregate data. 


\subsection{Explanation 1: Changes in production technology}

An obvious reason that oil shocks may no longer have much effect on inflation is that firms have substituted away from oil as a factor of production. As oil prices shot up following the embargo in October 1973, and later as firms came to realize that energy costs were not likely to return to their previous levels, energy conservation became a priority. ${ }^{5}$ There was a dramatic decrease in the number of BTU's of energy used per dollar of output in the 1970's (see e.g. Figure 1 of Sue Wing (2008)). On the other hand,

"To our considerable surprise, the industry-level data show that the fixed-weight average energy cost share rose by nearly a quarter between 1972 and $1994 \ldots$... In other words, the average 4-digit industry shifted toward more energy-intensive production technologies between 1972 and 1994." (Davis and Haltiwanger 2001)

Thus, production of a given amount of output currently uses less energy than it would have in 1973, but that is at least partially offset by the higher price of energy. In addition,

"The decline in the energy intensity of GDP does not seem responsible, as a sharp reduction in the sensitivity of inflation to oil prices remains in regressions that control for it." (Hooker 2002)

Our energy intensity measure comes from the 35 KLEM dataset downloaded from Professor Dale Jorgenson's homepage. ${ }^{6}$ The 35 KLEM data include annual observations on the price of output that producers receive, the quantity of output, and the value of capital, labor, energy, and materials inputs for each of 35 industries. Energy intensity for a given industry is calculated as the dollar value of energy inputs divided by the dollar value of total industry output. Unfortunately, the sectors in the 
disaggregate inflation dataset from the BEA are not classified by the same industry groups as the 35 KLEM data, so we had to match the energy intensity for each sector in our disaggregate inflation dataset with the energy intensity of the KLEM industry sharing that sector's SIC code.

In most cases, the SIC codes for the disaggregate inflation data were pulled from the U.S. Census Bureau's Bridge Between NAICS and SIC, and the SIC codes for the KLEM data were taken from Jorgenson and Stiroh (2000). In a few cases, a sector in the disaggregate inflation data included more than one of the KLEM industries, so we used the average of the energy intensity of the industries weighted according to their expenditure shares. The variable that enters the regression, the change in energy intensity of a sector, is the average energy intensity over 1986-2006 minus the average energy intensity over 1973-1985.

\subsection{Explanation 2: Monetary policy}

A second explanation is that there was a change in the conduct of monetary policy. The Federal Reserve, concerned with the employment effects of oil shocks, may have followed an accommodative monetary policy in the 1970's, or as suggested by Romer and Romer (2002), simply lacked a proper understanding of the inflationary effects of supply shocks. There is no consensus in the literature as to whether this is an accurate assessment. Bernanke, Gertler and Watson (1997) concluded that the recessions of the 1970's would not have occurred if the Federal Reserve had not tightened monetary policy in response to the oil shocks of that period. If Bernanke, Gertler and Watson's conclusion is correct, the Federal Reserve could not have been accommodating oil shocks in the 1970's.

Less plausible is that in recent years the Federal Reserve has acted to prevent 
changes in the price of oil from passing through to the broader economy. Blinder and Reis (2005, pages 44-47) cast doubt on this explanation, calling Greenspan's focus on core inflation an "innovation", given his belief that it did not make sense for the Federal Reserve to respond to oil shocks. They explain:

"In the United States today, an oil shock is viewed as a 'blip' to the inflation process that does not affect long-term inflationary expectations and should mostly be ignored by the Fed because it will fade away of its own accord." (Blinder and Reis 2005, p. 44)

In addition, Hooker (2002) found no evidence that the Federal Reserve was less accommodative of oil shocks in recent years than in the 1970's.

Discussions of monetary policy in the 1970's frequently emphasize the importance of credibility. Blanchard and Gali (2009), for instance, distinguish between the actual policy rule

$$
i_{t}=\phi_{\pi} \pi_{q, t}
$$

where $i$ is the central bank's interest rate target and $\pi$ is the inflation rate, and the perceived policy rule

$$
i_{t}=\phi_{\pi}(1-\delta) \pi_{q, t}+\nu_{t},
$$

with $0<\delta \leq 1$. A value of $\delta$ much smaller than one in the 1973-1985 time period, but approximately equal to one after 1985, can explain the reduced effect of oil shocks. As the public learned about the Federal Reserve's commitment to low inflation, oil shocks would have had less effect, even without a change in the response of monetary policy.

Whichever of the above explanations is correct, if monetary policy is the culprit, the effect of oil shocks on inflation should be explained by the sensitivity of inflation 
in that sector to changes in interest rates. Sectors not responsive to monetary policy changes should not have seen a change in their response to an oil shock. ${ }^{7}$

For each sectoral inflation rate, we estimated equation (3) in Romer and Romer (2004), and set that sector's sensitivity to monetary policy variable, which we call $M_{o n}$, equal to the sum of the coefficients on the monetary shock. The estimation equation is

$$
\Delta p_{i t}=a_{0}+\sum_{k=1}^{11} a_{k} D_{k t}+\sum_{i=1}^{24} b_{i} \Delta p_{i, t-i}+\sum_{j=1}^{48} c_{j} S_{t-j}+e_{t}
$$

where $\Delta p_{i t}$ is the (linearly detrended) inflation rate of sector $i$ in period $t, D$ is a seasonal dummy variable, $S$ is the monetary policy shock, and $M o n_{i}=\sum_{j=1}^{48} c_{j}$.

A well-known complication with identifying the effects of monetary policy shocks on inflation is the "price puzzle", whereby the price level rises, or stays flat, for a significant period of time after the shock occurs (e.g. Hanson (2004)). The paper by Romer and Romer (2004) is not different in this respect. While they did not observe an increase in prices after a tightening of monetary policy, they did find a delay of about 18 months before the CPI was affected by monetary policy shocks. For our disaggregated data, we find a wide range of responses to monetary policy shocks in the first two years, with prices in many sectors starting to fall only after about 18 months have passed. Unlike Figure 4 of Romer and Romer (2004), the average response to a monetary policy shock in the disaggregated data is hump-shaped, with a rise in prices over the first 18 months, and then a dramatic decline as the horizon increases. It is difficult to interpret the $c_{j}$ coefficients for low values of $j$, so that if we ignore the price puzzle, we may incorrectly conclude that monetary policy played no role in the breakdown. This is an empirical question - whether including the short-horizon and medium-horizon responses to a monetary policy shock as separate regressors yields a better fit can be tested. We estimate versions of (2) where $M o n_{i}$ is replaced with 
$M o n_{1 i}=\sum_{j=1}^{18} c_{i j}$ and $\operatorname{Mon}_{2 i}=\sum_{j=19}^{48} c_{i j}$.

\subsection{Explanation 3: Changes in the labor market}

A third explanation is that labor markets have changed (Blanchard and Gali 2009). The declining influence of unions, technological changes that have reduced the costs of job search, and the disappearance of wage indexation, among other factors, are reasons that wages are more flexible today than they were in the 1970's. Greater wage flexibility will cause both the output and inflation responses to an oil shock to decline. If changes in the labor market are the primary cause of the breakdown, those sectors with low labor share should have been largely unaffected. Labor intensity was calculated in the same way as energy intensity, by matching the SIC codes in our sectoral inflation dataset to the labor intensity of the industries in Jorgenson's 35 KLEM dataset.

\subsection{A note on endogeneity of oil prices}

In a recent paper, Kilian (2009) argues that much of the historical variation in oil prices can be attributed to changes in the demand for oil. He constructs an index of global real economic activity and shows that shocks to this series have large effects on oil prices, US GDP, and the US CPI. While Kilian makes a compelling case in favor of the endogeneity of oil prices, and the points he makes are clearly important, there are two reasons to be skeptical that endogeneity of oil prices can explain the breakdown of the relationship between oil shocks and inflation that is the focus of this paper.

First, for endogeneity of oil prices to have been the cause of the breakdown, there would have to have been a large change in the importance of oil demand shocks 
relative to oil supply disruptions. There is no reason to believe that this type of change has occurred. Kilian's dataset goes back to 1975 and his results suggest that global oil demand fluctuations explain much of the change in the price of oil around all major oil shocks since that time.

Second, endogeneity of oil prices does not cause the same identification problems for inflation as it does for GDP. A shock to world output will cause US output and the price of oil to move in the same direction, while a shock to the supply of oil will cause them to move in opposite directions. In contrast, changes in the price of oil should be followed by movements in inflation in the same direction, regardless of whether oil prices are responding to a shock to world output or a disruption of oil supplies (although the impact of a given oil price movement will depend on the underlying shock that is driving oil prices). It is therefore not clear how endogeneity of oil prices can explain the breakdown of the relationship between oil prices and inflation.

As Kilian (2009) points out when discussing the interpretation of VAR models with oil prices:

"Under standard assumptions, the resulting response estimates will be asymptotically valid.... Nevertheless, since this expectation by construction reflects the average composition of oil demand and oil supply shocks in the sample period, these estimates may be misleading, when it comes to judging the macroeconomic effects of a specific oil price shock." (Kilian 2009)

Our interest is not in looking at specific oil price increases, but rather in the behavior of oil prices over samples covering many years. As we are unaware of any papers showing how endogeneity of oil prices can serve as an explanation for the breakdown of this relationship, and given that conventional economic theory suggests that 
both increases in aggregate demand and exogenous oil supply shocks will put upward pressure on consumer prices, we do not pursue this explanation.

\subsection{Empirical Model}

The estimation equation is

$$
\triangle I R F_{i}=\beta_{0}+\beta_{1} \triangle E I_{i}+\beta_{2} M_{o n}+\beta_{3} L I_{i}+\beta_{4} K I_{i}+\varepsilon_{i},
$$

where $\triangle I R F_{i}$ is the change in the cumulative 12-month impulse response function for sector $i$ between the 1973-1985 and 1986-2006 periods; $\triangle E I_{i}$ is the change in energy intensity of sector $i$ between the two time periods; $M o n_{i}$ is the response of inflation in sector $i$ to a monetary policy shock; $L I_{i}$ is the average value of labor intensity for sector $i$; and $K I_{i}$ is the average value of capital intensity of sector $i$. All variables were constructed as described above.

Our choice of methodology follows Davis and Haltiwanger (2001) and Carlino and DeFina (1998). Davis and Haltiwanger (2001) regressed the response of industry-level employment to an oil shock on energy intensity, capital intensity, average plant size, average plant age, and product durability. Carlino and DeFina (1998) regressed state responses to monetary policy on a variety of variables related to monetary policy. Our methodology is informative to the extent that the explanatory variables in (2) are able to capture the three explanations in section 4.3. 


\subsection{Empirical Results}

\subsubsection{Changes in Impulse Response Functions}

Figure 1 is a histogram summarizing the distribution of the change in impulse response function estimates for each of the 97 inflation rates in our sample. The horizontal axis is the change in cumulative response of one inflation rate in the 12 months following a doubling of the price of oil. A number on the x-axis of -0.02 , for example, represents a two percentage point decline in the estimated response of inflation between the 1973-1985 and 1986-2006 subsamples. As noted in Section 3, the impulse response functions are identified by applying a Choleski decomposition to a bivariate VAR model with inflation ordered ahead of the oil price change.

Figure 1 shows that the change in response of core inflation documented in previous studies was driven by a small number of sectors. Only $29 \%$ of sectors (representing $26 \%$ of core consumption) saw the response to a doubling of the price of oil fall by two

percentage points or more. On the other hand, $62 \%$ of sectors (representing $68 \%$ of consumption) saw changes of less than two percentage points in one direction or the other. ${ }^{8}$ Given the substantial variation across sectors, a disaggregate analysis has the potential to provide much information that is not available with aggregate inflation data.

Impulse response function estimates for 1959-1972 (not reported) are very imprecise. Both the range and magnitude of estimated impulse response functions, positive and negative, are much larger than for either $1973-1985$ or 1986-2006, and the estimated parameters in the underlying VAR models have much larger standard errors. This is almost certainly due to the limited variation in oil prices in this time period, but poses no problems for our investigation, as our interest is in explaining changes in the behavior of inflation between the 1973-1985 and 1986-2006 time periods. 


\subsubsection{Model Estimates}

Table 4 reports results for (2) and for simple regressions with $\triangle E I_{i}, M o n_{i}$, and $L I_{i}$ separately. Because $\mathrm{Mon}_{i}$ is the output of a previous regression, we need to make appropriate adjustments when computing standard errors. Our procedure for the regressions that include $M o n$, or $M$ on $_{1}$ and $M o n_{2}$, is as follows (for an introduction to Bayesian methods and Gibbs Sampling, see Koop (2003) or Lancaster (2004)):

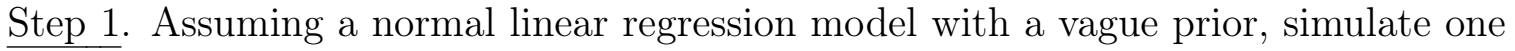
draw of the coefficients of the Romer and Romer equation

$$
\Delta p_{i t}=a_{0}+\sum_{k=1}^{11} a_{k} D_{k t}+\sum_{i=1}^{24} b_{i} \Delta p_{i, t-i}+\sum_{j=1}^{48} c_{j} S_{t-j}+e_{t}
$$

from a multivariate normal distribution as described by Lancaster (2004, p. 135), for each sector $i$. Those coefficients are then used to calculate the response to monetary policy shocks for each sector as above: $\operatorname{Mon}_{i}=\sum_{j=1}^{48} c_{j}{ }^{9}$

Step 2. Conditional on the $M_{o n}$ from step 1, take a draw of the coefficients from equation (2), again working with a normal linear regression model and a vague prior. Step 3. Repeat steps 1 and 2 a total of 10,000 times. The means of the coefficient draws in step 2 are the point estimates of the coefficients, and the standard deviations are the standard errors.

The first thing to note in Table 4 is that the change in energy intensity is significant in all regressions that it appears. The positive coefficients imply that sectors that became less energy-intensive showed a smaller reaction to oil shocks in the later period. For each percentage point decline in energy share, the response of inflation to a doubling of the price of oil fell between 1.23 and 1.36 percentage points. These estimates are reasonable. If oil shocks are completely passed on to consumers, the coefficient should be one. If oil price increases are followed by further increases, the 
coefficient should be greater than one. ${ }^{10}$

Mon is marginally insignificant when included in equations (2) and (5). However, as explained above, the well-known price puzzle might cause our regressions to underestimate the role of monetary policy. When we allow the initial and later responses to a monetary policy shock to enter the model separately (a specification supported by the data, with a test of equality of coefficients on $M o n_{1}$ and $M o n_{2}$ easily rejected), the coefficient on $\mathrm{Mon}_{2}$ is positive and significant. A stronger response to monetary policy shocks (i.e., a larger decrease in the inflation rate after a given increase in the federal funds rate) means inflation in that sector showed a weaker response to oil shocks in the 1986-2006 time period. There is no obvious interpretation of the coefficient on $\mathrm{Mon}_{1}$, as the delayed response of inflation to a monetary policy shock suggests that the coefficient should be zero in our regression, and is consistent with our results.

Neither labor intensity nor capital intensity enters the regression significantly. The point estimate of the coefficient on labor intensity is even positive. The coefficient should be negative if changes in the labor market were responsible for the breakdown, as those sectors with the greatest reliance on labor should have seen the largest decline in the impulse response function.

\subsubsection{Relative Importance of Variables}

The estimated coefficients in Table 4 are not easy to interpret beyond a test of statistical significance. The importance of an individual variable is a function of both the estimated coefficient and the variance of that variable. To calculate the contribution of individual variables to the decline in response of core inflation, we have done several counterfactual experiments. The calculations were done as follows.

Using the estimates of equation (6) in Table 4 , get fitted values for $\Delta I R F$ for all 
sectors using the actual data. Calculate the sum of these predicted values, denoted $\Delta I \widehat{R F}_{i}$, weighted by expenditure shares $w_{i}$ :

$$
\Delta I R F^{\text {Actual }}=\sum_{i=1}^{97} w_{i} \Delta I \widehat{R F}_{i}
$$

Now set the $\Delta E I$ series to zero for all observations, and make predictions for all observations, denoted $\triangle I \widehat{R F}_{i}^{E I}$. The predicted change in the effect of an oil shock on core inflation with no change in energy intensity is

$$
\Delta I R F^{\text {Energy }}=\sum_{i=1}^{97} w_{i} \Delta I \widehat{R F}_{i}^{E I}
$$

The effect of changes in energy intensity on the change in response to oil shocks, reported in the bottom panel of Table 4 , is

$$
\Delta I R F^{\text {Actual }}-\Delta I R F^{\text {Energy }} .
$$

A similar measure is constructed for the $M o n_{1}$ and $M o n_{2}$ variables by setting the $M o n_{1}$ and $M o n_{2}$ variables to zero. This is the same as asking what would have happened to $\triangle I R F$ if none of the sectors were responsive to monetary policy. Because there is no natural benchmark change in labor intensity to use in a counterfactual exercise to assess the importance of changes in the labor market, we reduced labor intensity for all observations by one standard deviation.

The results are reported in the bottom panel of Table 4 . The numbers are the contribution of each variable to the change in the response of aggregate core inflation after a doubling of the price of oil. Our results indicate that substitution away from energy in production is the primary reason that oil shocks no longer pass through to core inflation. The change in energy intensity explains twice as much of the break- 
down as monetary policy (-1.12\% for $\triangle E I$ versus $-0.57 \%$ for $\left.M_{0} n_{2}\right)$. Labor intensity explains only a trivial portion of the breakdown $(\triangle E I$ explains 14 times as much as labor intensity).

In addition to the changes that took place within individual sectors, there has also been a change in the composition of consumption. A shift away from energy-intensive manufacturing to services, for instance, represents a reduction in energy consumption that would be expected to cause $I R F$ to fall. One way to address this issue is to calculate how much the response of aggregate inflation in the 1973-1985 period would have changed if consumption shares in the 1973-1985 period were instead equal to their 1986-2006 values. Letting $I R F_{i}^{7385}$ be the impulse response function of sector $i$ during the 1973-1985 time period and $\triangle w_{i}$ be the change in average consumption share of sector $i$ between 1973-1985 and 1986-2006, we can calculate

$$
\sum_{i=1}^{97} \triangle w_{i} I R F_{i}^{7385} .
$$

This provides a rough estimate of how much the response of aggregate inflation changed due to a shift to sectors that are less sensitive to oil shocks. For our dataset, this calculation suggests that the response of aggregate inflation would have been only 0.16 percentage points lower in the 1973-1985 period if consumption shares had been at their 1986-2006 levels instead of their 1973-1985 levels. There does not appear to have been enough movement away from energy-intensive sectors to explain the breakdown of the oil price-inflation relationship.

\subsection{Statistical explanations}

This section considers two statistical explanations for the breakdown. It is possible that what appears to be a change in the effects of oil shocks may actually be the result 
of a small number of influential observations in one of the time periods. Alternatively, a large change in the persistence of oil shocks could cause a change in the estimated impulse response function. Suppose that the only response of inflation in either time period following a doubling of the price of oil is an immediate, permanent increase of one percentage point, $\pi_{t}=0.01 \mathrm{Oil}_{t}$, with no delayed response. In the early period, a doubling of the price of oil was followed by a $50 \%$ increase in the price of oil in the next month. In the recent period, a doubling of the price of oil was reversed over the next month.

The estimated 12-month cumulative impulse response function in this example would be $1.5 \%$ in the first period and $0 \%$ in the second. Even though the impulse response functions have changed, that change is driven entirely by a change in the time series behavior of the oil price, and has nothing to do with either the process generating inflation or passthrough of oil shocks to inflation. For example, the oil shock around the first Gulf War was short-lived relative to the oil shocks of the 1970's, and if this were true of all oil shocks in the 1986-2006 period, it could by itself explain the breakdown.

We have tested both of these explanations. We have redone the Granger causality tests of Table 2 for the core CPI in the two time periods, with observations having the largest Cook's distance measure being successively removed. Between one and ten potential outliers were eliminated. There is no evidence that the change in the effects of oil shocks on inflation was the result of outliers in either of the time periods. Even when the 10 largest potential outliers are removed, oil shocks have forecast power for the core CPI in the first time period, but not the second. Estimating impulse response functions for the core CPI using the VAR model discussed in Section 3, we find no major change in the persistence of oil shocks across the two time periods, certainly not in a way sufficient to explain the substantial change in the oil price-core inflation 
relationship. The $95 \%$ confidence intervals for the impulse response functions overlap at all horizons. These results are available from the authors upon request.

\section{Conclusion}

There has been a well-documented change in the effect of oil shocks on core CPI inflation. The oil shocks of the 1970's were followed by large increases in inflation, but for data after 1986, the response is much weaker or even nonexistent. We constructed measures of energy intensity, labor intensity, capital intensity, and sensitivity of inflation to monetary policy shocks for each sector of a dataset on inflation at a low level of aggregation. Changes in energy intensity and sensitivity to monetary policy shocks were found to be important determinants of the change in a sector's response to oil shocks between the 1973-1985 and 1986-2006 time periods. About two-thirds of the reduced response of aggregate inflation was due to the adoption of energy-conserving production methods and one-third to changes related to monetary policy. Given the dramatic decline in the inflationary effects of oil shocks, and the fact that much of that decline was due to energy conservation, future research might investigate the implications of government policies designed to reduce the economy's reliance on energy.

We have offered two explanations for our finding of the importance of monetary policy. The first is that the Federal Reserve accomodated oil shocks in the 1970's. Given the high (9\% by April 1975) and rapidly rising (3.9 percentage points from April 1974 to April 1975) unemployment rates at that time, there was substantial pressure on the Federal Reserve to pursue an expansionary monetary policy, and they may have decided that double-digit inflation was of secondary importance. Alternatively, the Federal Reserve may have lacked credibility, causing the public to 
expect a weak monetary policy response. In the later time period, after the public learned the Federal Reserve's reaction function, oil shocks were less inflationary. Both explanations point to the importance of systematic monetary policy, as argued by Bernanke, Gertler, and Watson (1997).

\section{References}

Andrews, Donald W.K. (1993) "Tests for Parameter Instability and Structural Change with Unknown Change Point." Econometrica, 61, 825-66.

Andrews, Donald W.K. and Werner Ploberger. (1994) "Optimal Tests When a Nuisance Parameter Is Present Only Under the Alternative." Econometrica, 62, $1383-1414$.

Barsky, Robert B. and Lutz Kilian. (2002) "Did Oil Shocks Really Cause the Great Stagflation of the 1970s?" In NBER Macroeconomics Annual 2001, edited by Ben Bernanke and Kenneth Rogoff, pp. 137-183.

Bernanke, Ben S. (2008). "Remarks on Class Day 2008." June 4, 2008, Harvard Magazine. http://harvardmagazine.com/commencement/bernanke-class-day-speech.

Bernanke, Ben S., Mark Gertler, and Mark Watson. (1997) "Systematic Monetary Policy and the Effects of Oil Price Shocks." Brookings Papers on Economic Activity, 1-1997, 91-124.

Blanchard, Olivier. (2009) Macroeconomics, 5th ed. Upper Saddle River, NJ: Pearson Prentice Hall.

Blanchard, Olivier and Jordi Gali. (2009) "The Macroeconomic Effects of Oil Shocks: Why Are the 2000's So Different from the 1970's?" In International Dimensions of Monetary Policy, edited by Jordi Gali and Mark Gertler, pp. 373-428. Chicago: University of Chicago Press. 
Blinder, Alan and Ricardo A.M.R. Reis. (2005) "Understanding the Greenspan Standard." In The Greenspan Era: Lessons for the Future, Federal Reserve Bank of Kansas City, pp. 11-96. Federal Reserve Bank of Kansas City.

Carlino, Gerald A. and Robert DeFina. (1998) "The Differential Regional Effects of Monetary Policy." Review of Economics and Statistics, 80, 572-87.

Clarida, Richard, Jordi Gali, and Mark Gertler. (2000) "Monetary Policy Rules and Macroeconomic Stability: Evidence and Some Theory." Quarterly Journal of Economics, 115, 147-80.

Davis, Steven J. and John Haltiwanger. (2001) "Sectoral Job Creation and Destruction Responses to Oil Price Changes." Journal of Monetary Economics, 48, 465-512.

De Gregorio, Jose, Oscar Landerretche, and Christopher Neilson. (2007) "Another Passthrough Bites the Dust? Oil Prices and Inflation." Economia, 7, 45-65.

Hanson, Michael S. (2004) "The 'Price Puzzle' Reconsidered." Journal of Monetary Economics, 51, 1385-1413.

Hooker, Mark A. (2002) "Are Oil Shocks Inflationary? Asymmetric and Nonlinear Specifications versus Changes in Regime." Journal of Money, Credit and Banking, 34, $540-61$.

Jones, Charles I. (2008) Macroeconomics. New York, NY: Norton.

Jorgenson, Dale W. and Kevin J. Stiroh. (2000) "Raising the Speed Limit: U.S. Economic Growth in the Information Age." Brookings Papers on Economic Activity, $31,125-236$.

Kilian, Lutz. (2009) "Not All Oil Price Shocks Are Alike: Disentangling Demand and Supply Shocks in the Crude Oil Market." American Economic Review, 99, 105369.

Koop, Gary. (2003) Bayesian Econometrics, John Wiley and Sons. 
Lancaster, Tony. (2004) Introduction to Modern Bayesian Econometrics, WileyBlackwell.

Nixon, Richard M. (1971) "Energy Resources." Speech to Congress, June 4, 1971.

R Development Core Team. (2008) "R: A Language and Environment for Statistical Computing." R Foundation for Statistical Computing, Vienna, Austria.

Romer, Christina D. and David H. Romer. (2002) "The Evolution of Economic Understanding and Postwar Stabilization Policy." In Rethinking Stabilization Policy, Federal Reserve Bank of Kansas City, pp. 11-78. Federal Reserve Bank of Kansas City.

Romer, Christina D. and David H. Romer. (2004) "A New Measure of Monetary Shocks: Derivation and Implications." American Economic Review, 94, 1055-84.

Sue Wing, Ian. (2008) "Explaining the Decline in U.S. Energy Intensity." Resource and Energy Economics, 30, 21-49.

Zeileis, Achim, Friedrich Leisch, Kurt Hornik and Christian Kleiber. (2002) "strucchange: An R Package for Testing for Structural Change in Linear Regression Models." Journal of Statistical Software, 7, 1-38. 


\section{Notes}

${ }^{1}$ See e.g. Barsky and Kilian (2002) for an alternative interpretation of what happened in the 1970's.

${ }^{2}$ The BEA made important changes to the data in 2009. The data used in this paper can be found at http://www.bea.gov/histdata/Releases/GDP_and_PI/2008/Q4/Final_March-26-2009/UND/Section2ALL_xls.xls.

${ }^{3}$ The break date was chosen by grid search to minimize the sum of squared errors. Using the sup F or exp F tests has no effect on the test results. For further details, see Zeileis, et al (2002).

${ }^{4}$ For the 1973-1985 time period, for example, we have only 156 observations.

${ }^{5}$ Energy prices began rising well in advance of the 1973 embargo. President Nixon gave a speech in 1971 in which he said,

“...the assumption that sufficient energy will always be readily available has been brought sharply into question within the last year....the possible shortages of fuel that were threatened last fall, the sharp increases in certain fuel prices...have all demonstrated that we cannot take our energy supply for granted any longer." (Nixon 1971)

Nonetheless, the price spike accompanying the 1973 shock was much larger and received more attention than previous energy price changes.

${ }^{6}$ The data were downloaded in 2007 from http://post.economics.harvard.edu/faculty/jorgenson/data.html.

${ }^{7}$ Our methodology is limited, in that it only captures the effects of monetary policy that follow from a change in interest rates, yet monetary policy can affect the economy in other ways.

${ }^{8}$ We are making no claims about whether a change in the response to an oil shock of two percentage points is in some economic sense "small". What is relevant for the purposes of this paper is that the change in response of aggregate inflation was actually a change in less than $30 \%$ of the economy.

${ }^{9}$ The sectoral inflation rates are linearly detrended. Some of the inflation rates exhibited obvious trends.

${ }^{10}$ To see this, assume that energy's share falls from $5 \%$ to $4 \%$. The effect of a doubling of the price of oil will fall by one percentage point, from $5 \%$ to $4 \%$. If a doubling of the price of oil at time $t$ is followed by an additional $36 \%$ rise in period $t+1$, the estimated coefficient will be 1.36 . The actual inflation process is no doubt more complicated than this simple example, but the estimated coefficient (making allowance for sampling error) is in an economically sensible range. 


\begin{tabular}{|c|c|c|}
\hline Sector Name & $\begin{array}{l}\text { Change in } \\
\text { IRF }\end{array}$ & $\begin{array}{c}\text { Response to Mon } \\
\text { Policy Shock }\end{array}$ \\
\hline New domestic autos & -0.061 & -0.008 \\
\hline New foreign autos & -0.061 & -0.008 \\
\hline Net transactions in used autos & 0.071 & 0.010 \\
\hline Used auto margin & 0.086 & 0.012 \\
\hline Employee reimbursement & 0.002 & -0.018 \\
\hline Trucks, new and net used & 0.008 & -0.009 \\
\hline Recreational vehicles & -0.017 & -0.045 \\
\hline Tires and tubes & -0.023 & -0.039 \\
\hline Accessories and parts & 0.004 & -0.017 \\
\hline Major household appliances & -0.015 & -0.013 \\
\hline Small electric appliances & -0.011 & -0.005 \\
\hline Video and audio goods, including musical instruments & 0.001 & -0.023 \\
\hline Floor coverings & 0.019 & -0.036 \\
\hline Durable house furnishings, n.e.c. & -0.012 & -0.028 \\
\hline Writing equipment & 0.008 & 0.008 \\
\hline Hand tools & 0.004 & -0.018 \\
\hline $\begin{array}{l}\text { Sports and photographic equipment, bicycles } \\
\text { and motorcycles }\end{array}$ & -0.057 & -0.016 \\
\hline Pleasure boats and aircraft & -0.017 & -0.046 \\
\hline Clothing and sewing for females & 0.008 & -0.003 \\
\hline Luggage for females & -0.115 & -0.064 \\
\hline $\begin{array}{l}\text { Men's and boys' clothing, sewing goods, and luggage, } \\
\text { except military issue }\end{array}$ & 0.002 & 0.002 \\
\hline
\end{tabular}




\section{Table 1: Oil Shocks and Core CPI Inflation in Selected Time Periods}

\begin{tabular}{|c|c|c|c|c|c|}
\hline Year & $\Delta W T I$ & $\Delta P^{\text {Core }}$ & Year & $\Delta W T I$ & $\Delta P^{\text {Core }}$ \\
\hline 1971 & $0 \%$ & $3.3 \%$ & $\overline{1978}$ & $0 \%$ & $8.2 \%$ \\
\hline 1972 & $0 \%$ & $2.5 \%$ & 1979 & $78.3 \%$ & $11.3 \%$ \\
\hline 1973 & $104.4 \%$ & $5.0 \%$ & 1980 & $15.6 \%$ & $10.7 \%$ \\
\hline 1974 & $9.9 \%$ & $10.9 \%$ & 1981 & $-11.6 \%$ & $8.8 \%$ \\
\hline 1975 & $0 \%$ & $6.7 \%$ & 1982 & $-8.2 \%$ & $4.5 \%$ \\
\hline
\end{tabular}

b: Recent Period

\begin{tabular}{|c|c|c|c|c|c|c|c|c|}
\hline Year & $\Delta W T I$ & $\Delta P^{\text {Core }}$ & Year & $\Delta W T I$ & $\Delta P^{\text {Core }}$ & Year & $\Delta W T I$ & $\Delta P^{\text {Core }}$ \\
\hline$\overline{1987}$ & $-8.4 \%$ & $4.2 \%$ & $\overline{1996}$ & $\overline{28.8 \%}$ & $2.5 \%$ & $\overline{2002}$ & $51.6 \%$ & $1.9 \%$ \\
\hline 1988 & $4.7 \%$ & $4.5 \%$ & 1997 & $-41.0 \%$ & $2.2 \%$ & 2003 & $4.0 \%$ & $1.2 \%$ \\
\hline 1989 & $23.0 \%$ & $4.3 \%$ & 1998 & $-29.3 \%$ & $2.3 \%$ & 2004 & $31.2 \%$ & $2.2 \%$ \\
\hline 1990 & $9.7 \%$ & $5.5 \%$ & 1999 & $77.9 \%$ & $2.1 \%$ & 2005 & $33.5 \%$ & $2.1 \%$ \\
\hline 1991 & $-28.2 \%$ & $3.9 \%$ & 2000 & $8.5 \%$ & $2.5 \%$ & 2006 & $4.3 \%$ & $2.6 \%$ \\
\hline
\end{tabular}

Notes: $\triangle W T I$ is the percentage change in the spot price of West Texas Intermediate crude oil. $\triangle P^{\text {Core }}$ is the percentage change in the Consumer Price Index for All Urban Consumers: All Items Less Food \& Energy. Source: Federal Reserve Bank of St. Louis. 
Table 2: Structural Break Tests for Aggregate Inflation Data

\begin{tabular}{lccccc}
\hline Variable & Break Date & ave F & pre-Break & post-Break & $1986-2006$ \\
\hline CPI & Feb 1980 & 0.00 & 0.12 & 0.00 & 0.00 \\
& & & $(0.007)$ & $(0.009)$ & $(0.010)$ \\
Core CPI & Mar 1980 & 0.00 & 0.00 & 0.96 & 0.52 \\
& & & $(0.034)$ & $(0.000)$ & $(0.003)$ \\
PCE Deflator & Jan 1981 & \multirow{2}{*}{0.00} & 0.08 & 0.00 & 0.00 \\
& & & $(0.008)$ & $(0.011)$ & $(0.011)$ \\
PCE Durables & Feb 1980 & 0.00 & 0.00 & 0.46 & 0.49 \\
& & & $(0.028)$ & $(0.002)$ & $(0.002)$ \\
PCE Nondurables & Feb 1981 & 0.00 & 0.03 & 0.00 & 0.00 \\
& & & $(0.007)$ & $(0.051)$ & $(0.051)$ \\
PCE Services & May 1984 & 0.00 & 0.03 & 0.05 & 0.06 \\
& & & $(0.018)$ & $(0.001)$ & $(0.001)$ \\
\hline
\end{tabular}

Notes: The estimated model is

$$
\pi_{t}=\alpha+\sum_{i=1}^{k} \beta_{i} \pi_{t-i}+\sum_{i=1}^{k} \gamma_{i} \triangle O i l_{t-i}+\varepsilon_{t}
$$

where $k$ is chosen to minimize the Akaike information criteria. The second and third columns are the estimated break date and p-value for the Andrews (1993) structural break test on $\left(\gamma_{1}, \ldots, \gamma_{k}\right)$. Columns 4 and 5 are the p-values for a test of $\gamma_{1}=\cdots=$ $\gamma_{k}=0$ on the pre-break and post-break subsamples. Column 6 is the p-value for a test of $\gamma_{1}=\cdots=\gamma_{k}=0$ for the 1986-2006 subsample. The sum of coefficients on the oil shock is in parenthesis. 
Table 3: Validity of Identified Oil Shocks

\begin{tabular}{|c|c|c|c|}
\hline \multicolumn{4}{|c|}{$\begin{array}{l}\text { A: Correlations of identified oil shock } \\
\text { with macroeconomic variables }\end{array}$} \\
\hline $\operatorname{corr}\left(\varepsilon_{t}^{W T I}, u_{t}\right)$ & \multicolumn{3}{|c|}{-0.05} \\
\hline $\operatorname{corr}\left(\varepsilon_{t}^{W T I}, \triangle I P_{t}\right)$ & \multicolumn{3}{|c|}{0.00} \\
\hline $\operatorname{corr}\left(\varepsilon_{t}^{W T I}, \triangle P C_{1 t}\right)$ & \multicolumn{3}{|c|}{0.00} \\
\hline $\operatorname{corr}\left(\varepsilon_{t}^{W T I}, F F R_{t}\right)^{\prime}$ & \multicolumn{3}{|c|}{-0.01} \\
\hline $\operatorname{corr}\left(\varepsilon_{t}^{W T I}, s_{t}^{\text {Romer }}\right)$ & \multicolumn{3}{|c|}{0.01} \\
\hline \multicolumn{4}{|c|}{$\begin{array}{l}\text { B: Regressions of identified oil shock } \\
\text { on macroeconomic variables }\end{array}$} \\
\hline Variable Name & $\underline{R}^{2}$ & F-stat & $\underline{\mathrm{p} \text {-value }}$ \\
\hline $\bar{u}$ & 0.02 & 0.75 & 0.71 \\
\hline$\triangle I P$ & 0.02 & 0.65 & 0.81 \\
\hline$\triangle P C_{1}$ & 0.02 & 0.76 & 0.70 \\
\hline$F F R$ & 0.02 & 0.72 & 0.74 \\
\hline$s^{\text {Romer }}$ & 0.02 & 0.52 & 0.91 \\
\hline
\end{tabular}

Notes: The variables are the identified oil shock $\left(\varepsilon^{W T I}\right)$, the total civilian unemployment rate $(u)$, industrial production growth $(\triangle I P)$, the growth rate of the first principle component of 63 macroeconomic series $\left(\triangle P C_{1}\right)$, the effective federal funds rate $(F F R)$, and the monetary policy shock series of Romer and Romer (2004) $\left(s^{\text {Romer }}\right)$. The regressions in panel B are for equation (1) in the text. 
Table 4: Explaining the Change in Response to Oil Shocks

\begin{tabular}{ccccccc}
\hline & $(1)$ & $(2)$ & $(3)$ & $(4)$ & $(5)$ & $(6)$ \\
$\beta_{0}$ & -0.00 & -0.01 & -0.01 & -0.02 & -0.03 & -0.03 \\
& $(-0.44)$ & $(-1.47)$ & $(-0.77)$ & $(-0.86)$ & $(-1.17)$ & $(-1.13)$ \\
$\triangle E I$ & 1.29 & & & & 1.36 & 1.23 \\
& $(2.16)$ & & & & $(2.23)$ & $(2.00)$ \\
Mon & & 0.44 & & & 0.35 & \\
& & $(1.88)$ & & & $(1.66)$ & \\
Mon $_{1}$ & & & 0.00 & & & -0.17 \\
& & & $(0.00)$ & & & $(-0.32)$ \\
Mon $_{2}$ & & & 0.60 & & & 0.52 \\
& & & $(2.38)$ & & & $(2.22)$ \\
LI & & & & 0.01 & 0.05 & 0.06 \\
& & & & $(0.18)$ & $(0.81)$ & $(1.04)$ \\
KI & & & & & 0.08 & 0.06 \\
& & & & & $(1.11)$ & $(0.94)$ \\
F-stat & 4.64 & 8.60 & 4.68 & 0.03 & 3.29 & 2.93 \\
p-value & 0.03 & 0.00 & 0.01 & 0.86 & 0.01 & 0.02 \\
$R^{2}$ & 0.05 & 0.08 & 0.09 & 0.00 & 0.13 & 0.14
\end{tabular}

Contribution of Variables to Change in Response of Inflation

$\begin{array}{cc}\triangle E I & -1.12 \% \\ \text { Mon }_{1} & -0.06 \% \\ \text { Mon }_{2} & -0.57 \% \\ L I & -0.08 \%\end{array}$

Notes: The dependent variable is the change in $I R F_{i}$ between the 1973-1985 period and the 1986-2006 period, where $I R F_{i}$ is the cumulative 12-month impulse response function for inflation in sector $i$ following a shock that doubles the price of oil. The bottom panel is the change in the response of aggregate inflation to oil shocks that is due to each of the variables. The variables are the change in energy share between 1973-1985 and 1986-2006 $(\triangle E I)$, response to monetary policy shocks $\left(M_{0} n_{1}\right.$ and $M_{o n}$ ), labor intensity (LI), and capital intensity (KI). t-statistics are in parenthesis. There are 97 observations in each regression. 


\begin{tabular}{|c|c|c|}
\hline Sector Name & $\begin{array}{c}\text { Change in } \\
\text { IRF }\end{array}$ & $\begin{array}{c}\text { Response to Mon } \\
\text { Policy Shock }\end{array}$ \\
\hline Standard clothing issued to military personnel & -0.010 & -0.007 \\
\hline Soap & -0.017 & -0.003 \\
\hline Cosmetics and perfumes & -0.010 & 0.002 \\
\hline Other personal hygiene goods & -0.004 & -0.011 \\
\hline Cleaning preparations & -0.125 & -0.008 \\
\hline Lighting supplies & 0.020 & -0.005 \\
\hline Paper products & -0.180 & -0.020 \\
\hline Prescription drugs & -0.003 & -0.003 \\
\hline Nonprescription drugs & 0.004 & -0.009 \\
\hline Medical supplies & -0.001 & -0.008 \\
\hline Gynecological goods & -0.003 & -0.011 \\
\hline Toys, dolls, and games & -0.058 & -0.017 \\
\hline Sport supplies, including ammunition & -0.054 & -0.017 \\
\hline Film and photo supplies & -0.004 & -0.008 \\
\hline Stationery and school supplies & -0.160 & -0.018 \\
\hline Greeting cards & -0.160 & -0.019 \\
\hline Expenditures abroad by U.S. residents & -0.202 & -0.042 \\
\hline Less: Personal remittances in kind to nonresidents & -0.008 & -0.026 \\
\hline Magazines and sheet music & 0.012 & 0.011 \\
\hline Newspapers & -0.102 & -0.011 \\
\hline Owner occupied mobile homes & 0.006 & -0.003 \\
\hline Owner occupied stationary homes & 0.006 & -0.002 \\
\hline Tenant occupied mobile homes & -0.002 & -0.001 \\
\hline
\end{tabular}




\begin{tabular}{|c|c|c|}
\hline Sector Name & $\begin{array}{l}\text { Change in } \\
\text { IRF }\end{array}$ & $\begin{array}{l}\text { Response to Mon } \\
\text { Policy Shock }\end{array}$ \\
\hline Tenant occupied stationary homes & 0.002 & -0.001 \\
\hline Tenant landlord durables & 0.012 & 0.000 \\
\hline Hotels and motels & 0.007 & -0.037 \\
\hline Clubs and fraternity housing & -0.013 & -0.003 \\
\hline Higher education housing & -0.003 & -0.001 \\
\hline Elementary and secondary education housing & 0.040 & 0.028 \\
\hline Tenant group room and board & -0.005 & -0.004 \\
\hline Tenant group employee lodging & 0.015 & -0.022 \\
\hline Water and other sanitary services & 0.005 & 0.009 \\
\hline Telephone and telegraph & -0.010 & 0.008 \\
\hline Domestic service & -0.042 & -0.011 \\
\hline Other other household operation & -0.044 & 0.003 \\
\hline $\begin{array}{l}\text { Repair, greasing, washing, parking, storage, } \\
\text { rental, and leasing }\end{array}$ & -0.040 & -0.012 \\
\hline Other user-operated transportation & -0.053 & 0.128 \\
\hline Mass transit systems & 0.006 & 0.002 \\
\hline Taxicab & -0.075 & -0.025 \\
\hline Railway & -0.093 & -0.014 \\
\hline Bus & 0.009 & 0.032 \\
\hline Airline & 0.022 & -0.045 \\
\hline Other intercity purchased transportation & 0.011 & 0.000 \\
\hline Hospitals & -0.007 & -0.013 \\
\hline Nursing homes & -0.034 & -0.037 \\
\hline
\end{tabular}




\begin{tabular}{|c|c|c|}
\hline Sector Name & $\begin{array}{c}\text { Change in } \\
\text { IRF }\end{array}$ & $\begin{array}{c}\text { Response to Mon } \\
\text { Policy Shock }\end{array}$ \\
\hline Medical care and hospitalization & 0.043 & 0.027 \\
\hline Income loss & 0.202 & 0.052 \\
\hline Workers' compensation & 0.000 & -0.009 \\
\hline Motion picture theaters & 0.001 & 0.001 \\
\hline Legitimate theaters and opera, and entertainments of & -0.009 & 0.001 \\
\hline \multicolumn{3}{|l|}{ nonprofit institutions (except athletics) } \\
\hline Spectator sports & 0.013 & 0.002 \\
\hline Radio and television repair & -0.005 & 0.003 \\
\hline Clubs and fraternal organizations & -0.013 & -0.047 \\
\hline Commercial participant amusements & 0.023 & -0.010 \\
\hline Pari-mutuel net receipts & 0.020 & 0.012 \\
\hline Other other recreation & 0.007 & -0.012 \\
\hline Cleaning, storage, and repair of clothing and shoes & -0.016 & -0.015 \\
\hline Barbershops, beauty parlors, and health clubs & 0.005 & 0.001 \\
\hline Other personal care & -0.024 & -0.013 \\
\hline Brokerage charges and investment counseling & -0.004 & -0.082 \\
\hline Bank service charges, trust services, and safe deposit box rental & 0.034 & -0.004 \\
\hline Services furnished without payment by financial intermediaries & -0.042 & -0.008 \\
\hline \multicolumn{3}{|l|}{ except life insurance carriers } \\
\hline Expense of handling life insurance and pension plans & -0.040 & 0.003 \\
\hline Legal services & 0.003 & -0.004 \\
\hline Funeral and burial expenses & -0.024 & -0.018 \\
\hline Other personal business & -0.018 & -0.015 \\
\hline
\end{tabular}




\begin{tabular}{lcc}
\hline & Change in & Response to Mon \\
Sector Name & IRF & Policy Shock \\
\hline Higher education & -0.006 & -0.013 \\
Nursery, elementary, and secondary schools & -0.008 & -0.019 \\
Other education and research & -0.097 & -0.052 \\
Political organizations & -0.034 & -0.064 \\
Museums and libraries & 0.042 & -0.050 \\
Foundations to religion and welfare & -0.006 & -0.026 \\
Social welfare & -0.147 & -0.028 \\
Religion & -0.028 & -0.049 \\
Foreign travel by U.S. residents & -0.039 & -0.042 \\
Expenditures in the U.S. by nonresidents & 0.016 & -0.014 \\
\hline
\end{tabular}


Figure 1: Histogram of Changes in Sectoral Inflation Rate Responses

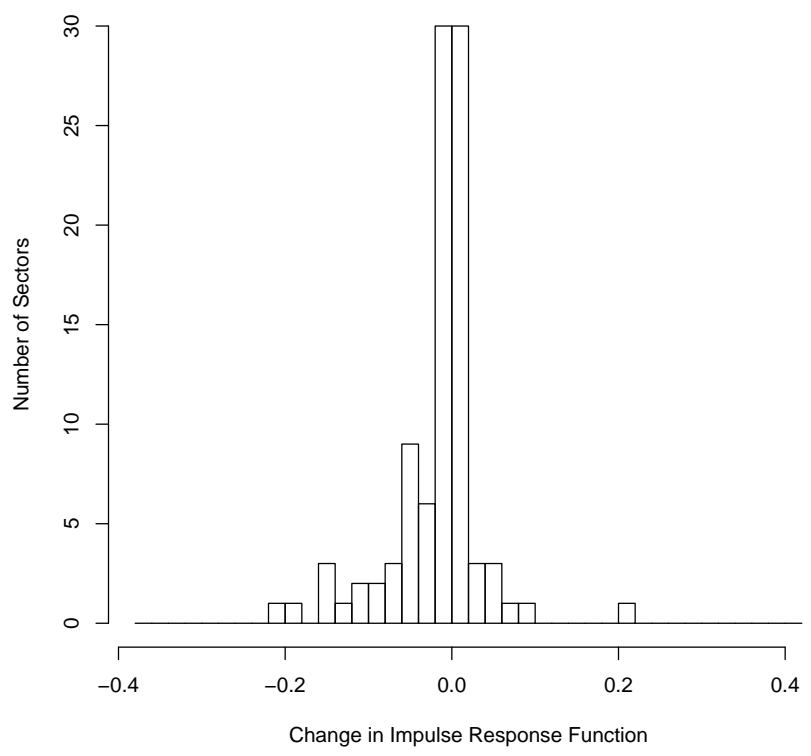

